Portland State University

PDXScholar

$12-1-2007$

\title{
Templated fabrication of large area subwavelength antireflection gratings on silicon
}

Chih-Hung Sun

University of Florida

Wei-Lun Min

University of Florida

Nicholas C. Linn

University of Florida

Peng Jiang

University of Florida

Bin Jiang

Portland State University

Follow this and additional works at: https://pdxscholar.library.pdx.edu/mth_fac

Part of the Mathematics Commons

Let us know how access to this document benefits you.

Citation Details

Sun, C., Min, W., Linn, N. C., Jiang, P., \& Jiang, B. (2007). Templated fabrication of large area subwavelength antireflection gratings on silicon. Applied Physics Letters, 91(23), 231105

This Article is brought to you for free and open access. It has been accepted for inclusion in Mathematics and Statistics Faculty Publications and Presentations by an authorized administrator of PDXScholar. Please contact us if we can make this document more accessible: pdxscholar@pdx.edu. 


\title{
Templated fabrication of large area subwavelength antireflection gratings on silicon
}

\author{
Chih-Hung Sun, Wei-Lun Min, Nicholas C. Linn, and Peng Jiang ${ }^{\text {a) }}$ \\ Department of Chemical Engineering, University of Florida, Gainesville, Florida 32611, USA \\ Bin Jiang \\ Department of Mathematics and Statistics, Portland State University, Portland, Oregon 97201, USA
}

(Received 2 October 2007; accepted 15 November 2007; published online 5 December 2007)

\begin{abstract}
We report a cheap and scalable bottom-up technique for fabricating wafer-scale, subwavelength-structured antireflection coatings on single-crystalline silicon substrates. Spin-coated monolayer colloidal crystals are utilized as shadow masks to generate metallic nanohole arrays. Inverted pyramid arrays in silicon can then be templated against nanoholes by anisotropic wet etching. The resulting subwavelength gratings greatly suppress specular reflection at normal incidence. The reflection spectra for flat silicon and the templated gratings at long wavelengths agree well with the simulated results using a rigorous coupled wave analysis model. These subwavelength gratings are of great technological importance in crystalline silicon solar cells. (C) 2007 American Institute of Physics. [DOI: 10.1063/1.2821833]
\end{abstract}

Current production of solar cells is dominated by crystalline silicon modules; ${ }^{1,2}$ however, due to the high refractive index of silicon, more than $30 \%$ of incident light is reflected back, which greatly reduces the conversion efficiency of photovoltaic devices. ${ }^{3-5}$ To significantly suppress the reflective loss of solar cells, various antireflection techniques, such as quarter-wavelength multilayer films and nanoporous coatings, have been developed. ${ }^{3,6-16}$ For crystalline silicon solar cells, silicon nitride films deposited by plasma enhanced chemical vapor deposition have become the industry standard for antireflection coatings (ARCs). ${ }^{3}$ Unfortunately, these existing techniques often perform suboptimally or are expensive to implement, impeding development of solar cells that can be made truly economically competitive with fossil fuels.

Inspired by the microstructured cornea of some nocturnal moths, ${ }^{17,18}$ subwavelength-structured gratings directly patterned on silicon substrates have been extensively explored both experimentally ${ }^{7,19-28}$ and theoretically ${ }^{29-32}$ for developing broadband ARCs. These gratings with a period smaller than the wavelength of incident light are intrinsically more stable and durable than multilayer ARCs since no foreign material is involved. Electron-beam lithography (EBL) is a common approach in fabricating subwavelength gratings. ${ }^{22,23}$ Unfortunately, the low throughput and the high cost of EBL raise big concerns. Interference lithography ${ }^{7,19}$ and nanoimprint lithography ${ }^{28}$ enable the creation of subwavelength antireflection structures over large areas; however, these techniques are still expensive to implement.

Here, we demonstrate a much simpler and cheaper selfassembly technology in creating wafer-scale subwavelength antireflection gratings on single-crystalline silicon substrates. Contrary to most bottom-up approaches, ${ }^{21,27}$ which are favorable for low-volume, laboratory-scale production, this nonlithographic technique is compatible with standard microfabrication, enabling large-scale production of subwavelength ARCs for solar collectors. The technology is based on

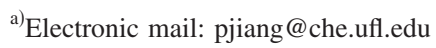

the robust spin-coating technological platform we have recently developed for scalable production of periodic nanostructured materials. ${ }^{33-38}$

A schematic illustration of the fabrication procedures for making wafer-scale subwavelength inverted pyramid gratings on single-crystalline silicon wafers is shown in Fig. 1. We start to generate nonclose-packed colloidal monolayers on a (100) silicon wafer (test grade, $n$ type, Montco Silicon Technologies) by the spin-coating technology. ${ }^{33,34}$ The nonclose-packed silica particles function as shadow masks during an electron-beam evaporation process for depositing a $30 \mathrm{~nm}$ thick chromium layer. After lifting off the templating silica particles, a periodic array of nanoholes whose diameter is determined by the size of templating silica spheres can be formed. ${ }^{36}$ These circular nanoholes can then be used as etching masks during a $\mathrm{KOH}$ anisotropic etching process to create wafer-scale inverted pyramid arrays in silicon substrates. ${ }^{37}$

We are able to control the pyramid size by simply adjusting the anisotropic etching conditions. Figure 2 shows

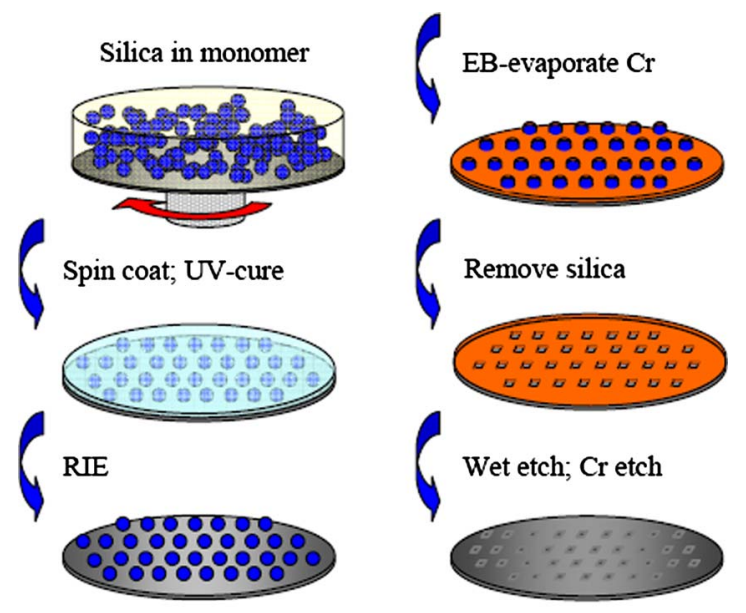

FIG. 1. (Color online) Schematic illustration of the templating procedures for fabricating subwavelength-structured antireflection pyramid gratings on single-crystalline silicon. 


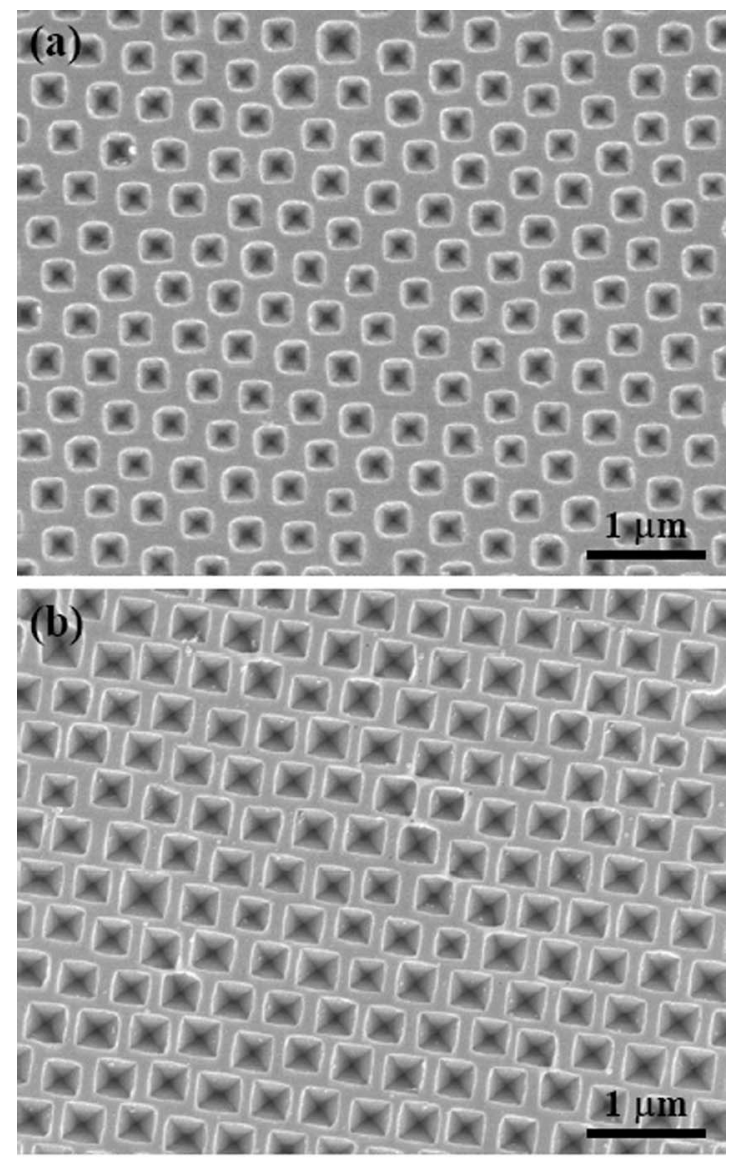

FIG. 2. Replicated inverted pyramid arrays in silicon. (a) The $300 \mathrm{~nm}$ size pyramids etched at $60{ }^{\circ} \mathrm{C}$ for $90 \mathrm{~s}$. (b) The $360 \mathrm{~nm}$ size pyramids etched at $60{ }^{\circ} \mathrm{C}$ for $210 \mathrm{~s}$. The $320 \mathrm{~nm}$ diameter silica spheres are used as templates.

scanning electron microscope (SEM) images of two inverted pyramid arrays templated from the same spin-coated silica monolayer sample (320 $\mathrm{nm}$ particle diameter). The samples are etched in the same solution containing $62.5 \mathrm{~g} \mathrm{KOH}$, $50 \mathrm{ml}$ anhydrous 2-propanol, and $200 \mathrm{ml}$ ultrapure water at $60{ }^{\circ} \mathrm{C}$ for 90 and $210 \mathrm{~s}$, respectively. It is apparent that longer etching leads to larger pyramids with well-defined square bases, while the less etched samples have rounded corners. The size of the pyramids can be larger than that of the templating silica spheres due to the undercutting of silicon substrates underneath chromium nanoholes. The longrange hexagonal ordering of the templated pyramidal pits is evident from the SEM images. The orthogonal crosses at the centers of the pits confirm the inverted pyramidal structures. ${ }^{39}$

The specular optical reflectivity of the replicated pyramid arrays is evaluated using visible-near-IR reflectivity measurement at normal incidence. ${ }^{35}$ The solid lines in Fig. 3 show the measured normal-incidence specular reflection from a polished (100) silicon wafer and the sample, shown in Fig. 2(b), with $360 \mathrm{~nm}$ pyramidal pits. The flat silicon substrate exhibits high reflection $(>35 \%)$ for visible and nearinfrared wavelengths, while the subwavelength-structured gratings show reduced reflection of $\sim 10 \%$ for long wavelengths $(>600 \mathrm{~nm})$. The reflection is further reduced to $\sim 2 \%$ for wavelengths around $400 \mathrm{~nm}$. For smaller pyramids, the reflection progressively increases with decreased pyramidal pits.

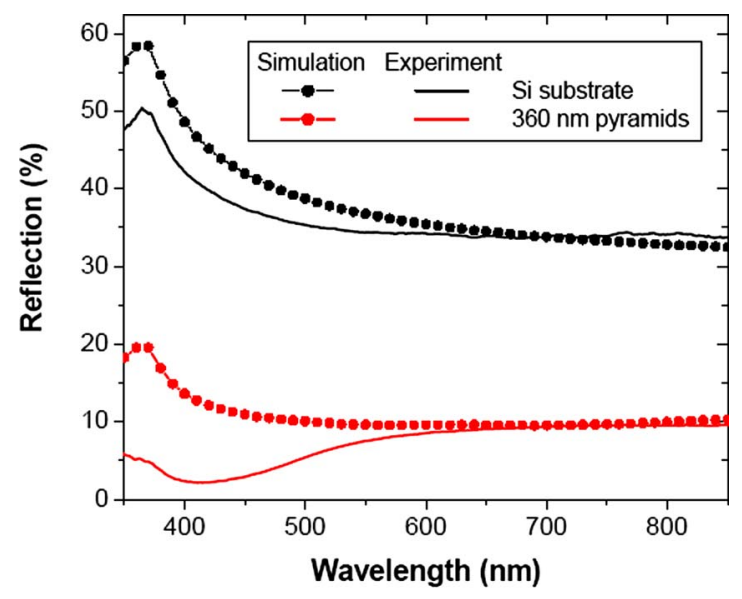

FIG. 3. (Color online) Experimental (solid) and RCWA-modeled (dotted) specular optical reflectivity at normal incidence. Black: bare (100) silicon wafer. Red: $360 \mathrm{~nm}$ size pyramids templated from $320 \mathrm{~nm}$ silica spheres.

The templated silicon subwavelength gratings exhibit lower reflection than colloid-based antireflection coatings on crystalline silicon solar cells. ${ }^{5}$ Though the normal-incidence reflection from the templated pyramid gratings is higher than other subwavelength-structured ARCs made by lithographic techniques with typical reflection of $\sim 2 \%-10 \%$, $7,19,22,23,28$ the cost benefit of this nonlithographic methodology is a major advantage. Additionally, optimization of the templated structures will facilitate further improvement of the antireflection performance. The state-of-the-art silicon nitride ARCs on crystalline silicon solar cells exhibit minimal $(<2 \%)$ reflection around $600 \mathrm{~nm}$, but the reflection increases to more than $10 \%$ for near-IR $(>800 \mathrm{~nm})$ and visible $(<500 \mathrm{~nm})$ wavelengths, which account for a significant portion of the solar spectrum. ${ }^{3,5}$ By contrast, the templated pyramid arrays show relatively low reflection at short wavelengths (Fig. 3).

A multilayer rigorous coupled wave analysis (RCWA) model $\mathrm{l}^{40-42}$ has also been developed to complement the optical measurement. Firstly, we divide the inverted pyramid array into 100 horizontal layers with equal thickness. Since the $\mathrm{KOH}-$ etched silicon pyramids have characteristic of $54.7^{\circ}$

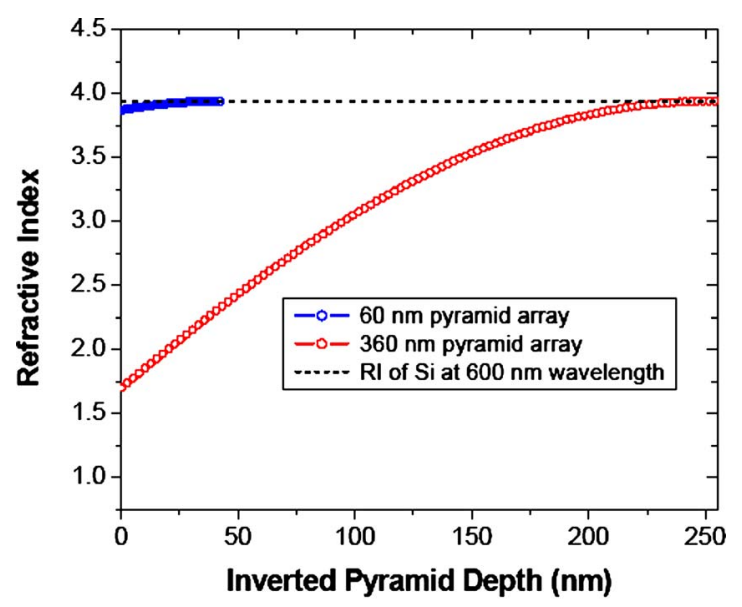

FIG. 4. (Color online) Comparison of the change of calculated effective refractive index at $\lambda=600 \mathrm{~nm}$ from the wafer surface (depth=0) to the vertex plane of inverted pyramids between a $360 \mathrm{~nm}$ pyramid array (red circles) and a $60 \mathrm{~nm}$ pyramid array (blue circles). The diameter of templating silica spheres is $320 \mathrm{~nm}$. 


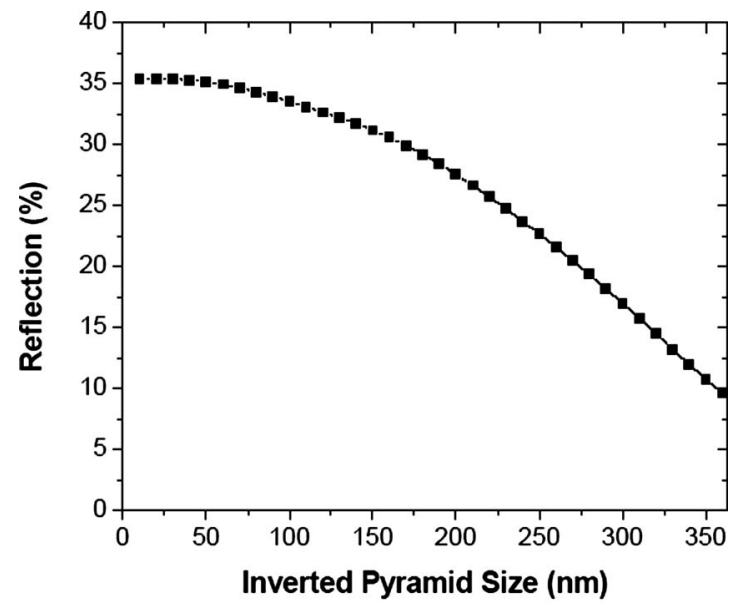

FIG. 5. RCWA-simulated normal-incidence optical reflection at $\lambda$ $=600 \mathrm{~nm}$ vs inverted pyramid size. The $320 \mathrm{~nm}$ silica spheres are used as templates.

sidewalls, the depth of the anisotropic V-shape pitches is determined by the base length of the pits. Based on the effective medium theory, ${ }^{43}$ the effective refractive index $n\left(z^{*}\right)$ of the layer at level $z^{*}$ can be approximated by $n\left(z^{*}\right)$ $=\left[f\left(z^{*}\right) \tilde{N}_{\mathrm{Si}}^{q}+\left[1-f\left(z^{*}\right)\right] n_{\mathrm{air}}^{q}\right]^{1 / q}$, where $f\left(z^{*}\right)$ is the fraction of silicon contained in the layer, $\widetilde{N}_{\mathrm{Si}}=n+i k$ is the complex refractive index of silicon ( $n$ and $k$ are optical constants), $n_{\text {air }}$ $=1$, and $q=\frac{2}{3} .{ }^{43}$ The optical constants of silicon which are functions of wavelengths are obtained from literature. ${ }^{44} \mathrm{Sec}-$ ondly, we calculate the reflectance of the whole system by solving the Maxwell equation to express the electromagnetic (EM) field in each layer and then match EM boundary conditions between neighboring layers for the determination of the reflectance of the system.

The RCWA-simulated reflection for a bare silicon substrate and an inverted pyramid array in silicon with $360 \mathrm{~nm}$ base length are shown by the dotted lines in Fig. 3. It is apparent that the theoretical prediction for single-crystalline silicon is close to the experimental spectrum, while for the subwavelength-structured pyramid gratings, the modeling results only match with experimental data when the wavelength is large. The difference tends to be large when the wavelength becomes small. This is due to the limitation of the modeling where each layer is assumed to have a uniform refractive index,${ }^{42}$ which is, in fact, a two-dimensional periodic function at each layer. Meanwhile, the effective refractive index formula is only accurate when the wavelength of light is larger than the period of the pyramid arrays. ${ }^{43}$

To understand the improved antireflection performance for subwavelength-structured pyramid arrays, we plot the calculated real part of the complex refractive index at $\lambda$ $=600 \mathrm{~nm}$ versus the depth of pyramids with $60 \mathrm{~nm}$ (blue circles) and $360 \mathrm{~nm}$ (red circles) base lengths in Fig. 4. For $60 \mathrm{~nm}$ size pyramids, the refractive index changes sharply at the interface between air and the structured silicon surface. The graded index, which is desirable for suppressing the optical reflection, ${ }^{18}$ is observed for $360 \mathrm{~nm}$ pyramids - the refractive index changes from 1.0 to $\sim 1.7$ at the air/silicon interface and then gradually changes to the bulk index of silicon. We further calculate the normal-incidence reflection at $\lambda=600 \mathrm{~nm}$ for pyramid array samples with different sizes and the results are shown in Fig. 5. It is apparent that larger pyramids lead to lower reflection, matching our experimental observation.

In summary, we have developed a cheap and scalable nonlithographic approach for creating subwavelengthstructured antireflection coatings directly on singlecrystalline silicon substrates.

This work was supported in part by the NSF under Grant No. CBET-0651780, the start-up funds from the University of Florida, and the UF Research Incentive Seed Fund.

${ }^{1}$ US Department of Energy Report of the Basic Energy Sciences Workshop on Solar Energy Utilization, 18-21 April 2005 (unpublished).

${ }^{2}$ Handbook of Photovoltaic Science and Engineering, edited by A. Luque and S. Hegedus (Wiley, West Sussex, 2003), p. 268.

${ }^{3}$ P. Doshi, G. E. Jellison, and A. Rohatgi, Appl. Opt. 36, 7826 (1997).

${ }^{4}$ A. Gombert, W. Glaubitt, K. Rose, J. Dreibholz, B. Blasi, A. Heinzel, D. Sporn, W. Doll, and V. Wittwer, Thin Solid Films 351, 73 (1999).

${ }^{5}$ B. G. Prevo, E. W. Hon, and O. D. Velev, J. Mater. Chem. 17, 791 (2007).

${ }^{6}$ D. G. Chen, Sol. Energy Mater. Sol. Cells 68, 313 (2001).

${ }^{7}$ P. Lalanne and G. M. Morris, Nanotechnology 8, 53 (1997).

${ }^{8}$ S. Chattopadhyay, L. C. Chen, and K. H. Chen, Crit. Rev. Solid State Mater. Sci. 31, 15 (2006).

${ }^{9}$ P. T. Hammond, Adv. Mater. (Weinheim, Ger.) 16, 1271 (2004).

${ }^{10}$ J. Hiller, J. D. Mendelsohn, and M. F. Rubner, Nat. Mater. 1, 59 (2002).

${ }^{11}$ M. Ibn-Elhaj and M. Schadt, Nature (London) 410, 796 (2001).

${ }^{12}$ H. Y. Koo, D. K. Yi, S. J. Yoo, and D. Y. Kim, Adv. Mater. (Weinheim, Ger.) 16, 274 (2004).

${ }^{13}$ B. G. Prevo, Y. Hwang, and O. D. Velev, Chem. Mater. 17, 3642 (2005).

${ }^{14}$ S. Walheim, E. Schaffer, J. Mlynek, and U. Steiner, Science 283, 520 (1999).

${ }^{15}$ Z. Z. Wu, J. Walish, A. Nolte, L. Zhai, R. E. Cohen, and M. F. Rubner, Adv. Mater. (Weinheim, Ger.) 18, 2699 (2006).

${ }^{16}$ J. Q. Xi, M. F. Schubert, J. K. Kim, E. F. Schubert, M. F. Chen, S. Y. Lin, W. Liu, and J. A. Smart, Nat. Photonics 1, 176 (2007).

${ }^{17}$ P. B. Clapham and M. C. Hutley, Nature (London) 244, 281 (1973).

${ }^{18}$ D. G. Stavenga, S. Foletti, G. Palasantzas, and K. Arikawa, Proc. R. Soc. London, Ser. B 273, 661 (2006).

${ }^{19}$ C. Aydin, A. Zaslavsky, G. J. Sonek, and J. Goldstein, Appl. Phys. Lett. 80, 2242 (2002).

${ }^{20}$ C. Heine and R. H. Morf, Appl. Opt. 34, 2476 (1995).

${ }^{21}$ Y. Kanamori, K. Hane, H. Sai, and H. Yugami, Appl. Phys. Lett. 78, 142 (2001).

${ }^{22}$ Y. Kanamori, E. Roy, and Y. Chen, Microelectron. Eng. 78-79, 287 (2005).

${ }^{23}$ Y. Kanamori, M. Sasaki, and K. Hane, Opt. Lett. 24, 1422 (1999).

${ }^{24}$ F. Nikolajeff, B. Lofving, M. Johansson, J. Bengtsson, S. Hard, and C. Heine, Appl. Opt. 39, 4842 (2000).

${ }^{25}$ C. C. Striemer and P. M. Fauchet, Appl. Phys. Lett. 81, 2980 (2002).

${ }^{26}$ S. Wang, X. Z. Yu, and H. T. Fan, Appl. Phys. Lett. 91, 061105 (2007).

${ }^{27}$ C. T. Wu, F. H. Ko, and C. H. Lin, Appl. Phys. Lett. 90, 171911 (2007).

${ }^{28}$ Z. N. Yu, H. Gao, W. Wu, H. X. Ge, and S. Y. Chou, J. Vac. Sci. Technol. B 21, 2874 (2003).

${ }^{29}$ E. B. Grann, M. G. Moharam, and D. A. Pommet, J. Opt. Soc. Am. A 12, 333 (1995).

${ }^{30}$ W. H. Southwell, J. Opt. Soc. Am. A 8, 549 (1991).

${ }^{31}$ B. S. Thornton, J. Opt. Soc. Am. 65, 267 (1975).

${ }^{32}$ J. Zhao and M. A. Green, IEEE Trans. Electron Devices 38, 1925 (1991).

${ }^{33}$ P. Jiang and M. J. McFarland, J. Am. Chem. Soc. 126, 13778 (2004).

${ }^{34}$ P. Jiang, T. Prasad, M. J. McFarland, and V. L. Colvin, Appl. Phys. Lett. 89, 011908 (2006).

${ }^{35}$ N. C. Linn, C. H. Sun, P. Jiang, and B. Jiang, Appl. Phys. Lett. 91, 101108 (2007).

${ }^{36}$ P. Jiang and M. J. McFarland, J. Am. Chem. Soc. 127, 3710 (2005).

${ }^{37}$ C. H. Sun, N. C. Linn, and P. Jiang, Chem. Mater. 19, 4551 (2007).

${ }^{38}$ P. Jiang, Langmuir 22, 3955 (2006).

${ }^{39}$ J. Henzie, E. S. Kwak, and T. W. Odom, Nano Lett. 5, 1199 (2005).

${ }^{40}$ M. G. Moharam and T. K. Gaylord, J. Opt. Soc. Am. 71, 811 (1981).

${ }^{41}$ M. G. Moharam and T. K. Gaylord, J. Opt. Soc. Am. A 3, 1780 (1986).

${ }^{42}$ M. G. Moharam, D. A. Pommet, E. B. Grann, and T. K. Gaylord, J. Opt. Soc. Am. A 12, 1077 (1995).

${ }^{43}$ H. A. Macleod, Thin-Film Optical Filters, 3rd ed. (Institute of Physics, Bristol, 2001), p. 40.

${ }^{44}$ M. A. Green and M. Keevers, Prog. Photovoltaics 3, 189 (1995). 
Applied Physics Letters is copyrighted by the American Institute of Physics (AIP). Redistribution of journal material is subject to the AIP online journal license and/or AIP copyright. For more information, see http://ojps.aip.org/aplo/aplcr.jsp 